Please do not remove this page

RMIT

UNIVERSITY

\title{
FOLFOX 4 combined with herbal medicine for advanced colorectal cancer: A systematic review
}

Chen, Meng; May, Brian; Zhou, Wenyu; Xue, Charlie Changli; Zhang, Anthony Lin

https://researchrepository.rmit.edu.au/esploro/outputs/9921859794601341/filesAndLinks?institution=61RMIT_INST\&index=null

Chen, M., May, B., Zhou, W., Xue, C. C., \& Zhang, A. L. (2014). FOLFOX 4 combined with herbal medicine for advanced colorectal cancer: A systematic review. Phytotherapy Research, 28(7), 976-991.

https://doi.org/10.1002/ptr.5092

Document Version: Accepted Manuscript

Published Version: https://doi.org/10.1002/ptr.5092

Repository homepage: https://researchrepository.rmit.edu.au

(c) 2013 John Wiley \& Sons, Ltd.

Downloaded On 2023/04/26 23:12:30 +1000

Please do not remove this page 
Thank you for downloading this document from the RMIT Research Repository.

The RMIT Research Repository is an open access database showcasing the research outputs of RMIT University researchers.

RMIT Research Repository: http://researchbank.rmit.edu.au/

\section{Citation:}

Chen, M, May, B, Zhou, W, Xue, C and Zhang, A 2013, 'FOLFOX 4 combined with herbal medicine for advanced colorectal cancer: A systematic review', Phytotherapy Research, pp. 1-16.

See this record in the RMIT Research Repository at:

https://researchbank.rmit.edu.au/view/rmit:23962

Version: Published Version

Copyright Statement:

(C) 2013 John Wiley \& Sons, Ltd.

Link to Published Version:

https://researchbank.rmit.edu.au/view/rmit:23962 


\section{FOLFOX 4 combined with herbal medicine for advanced colorectal cancer: a systematic review}

\begin{tabular}{|r|l|}
\hline Journal: & Phytotherapy Research \\
\hline Manuscript ID: & PTR-13-0758.R1 \\
\hline Date Submitted by the Author: & n/a \\
\hline Complete List of Authors: & $\begin{array}{l}\text { Chen, Menghua; RMIT University, Health Sciences } \\
\text { May, Brian; RMIT University, Health Sciences; } \\
\text { Zhou, Wenyu; RMIT University, Health Sciences } \\
\text { Xue, Charlie; RMIT University, Health Sciences } \\
\text { Zhang, Anthony; RMIT University, Health Sciences }\end{array}$ \\
\hline Keyword: & $\begin{array}{l}\text { colorectal cancer, FOLFOX, herbal medicine, tumor response, quality of life, } \\
\text { meta-analysis }\end{array}$ \\
\hline &
\end{tabular}

SCHOLARONE ${ }^{\text {"m }}$

Manuscripts 


\title{
FOLFOX 4 combined with herbal medicine for advanced colorectal cancer: a systematic review
}

\author{
Menghua Chen ${ }^{1}$, Brian H May ${ }^{1}$, Iris W Zhou ${ }^{1}$, Charlie CL Xue, ${ }^{1,2}$ Anthony L Zhang ${ }^{1 \S}$ \\ ${ }^{1}$ School of Health Sciences, and Traditional \& Complementary Medicine Research Program, Health \\ Innovations Research Institute, RMIT University, Bundoora, VIC 3083, Australia \\ ${ }^{2}$ Guangdong Provincial Academy of Chinese Medical Sciences \& Guangdong Provincial Hospital of \\ Chinese Medicine, Guangzhou, China \\ ${ }^{\S}$ Corresponding author: Dr Anthony L Zhang \\ Head of Discipline \\ School of Health Sciences, College of Science, Engineering and Health; \\ RMIT University, PO Box 71, Bundoora, Vic. 3083, Australia \\ Tel: +613 99257758, Fax: +61399257178 \\ E-mail: tony.zhang@rmit.edu.au
}

Email addresses of other authors (note: mailing address is as above for all authors):

Menghua Chen BMed: PhD candidate, RMIT University, aussway@yahoo.com.au

Brian H May PhD: Clinical Research Fellow, RMIT University, brian.may@rmit.edu.au

Iris W Zhou PhD: Research Fellow, RMIT University, wenyu.zhou@rmit.edu.au

Charlie CL Xue PhD: Head of School, RMIT University, charlie.xue@rmit.edu.au

Review article: 5604 words (body text), 2 tables, 2 figures

Running head: FOLFOX 4 plus herbal medicine for advanced CRC

Funding support: 1. The project is partially supported by an International Research Grant from the Guangdong Provincial Academy of Chinese Medical Sciences, Guangdong Province, China. 2.

Menghua Chen is supported by an Australian Postgraduate Award at RMIT University, Australia.

Conflict of interest disclosure: The authors have no financial interests or other conflicts of interest related to the material in this manuscript. This research is not under submission, in whole or in part, to other journals. All authors have contributed to the paper. 


\title{
Abstract
}

This systematic review evaluates the clinical evidence for the addition of herbal medicines (HMs) to FOLFOX 4 for advanced colorectal cancer (ACRC) in terms of tumor response rate (tRR), survival, quality of life and reduction in adverse events (AEs). Seven electronic databases were searched for randomized controlled trials (RCTs) of FOLFOX4 combined with HMs compared to FOLFOX4 alone. Outcome data for 13 randomized controlled trials were analysed using Review Manager 5.1. Risk of bias for objective outcomes including tumor response and survival was judged as low. Publication bias was not evident. Metaanalyses found the addition of HMs improved tRR (RR 1.25, 95\%CI 1.06-1.47, $\mathrm{I}^{2}=0 \%$ ), one year survival (RR 1.51, 95\%CI 1.19-1.90, $\mathrm{I}^{2}=0 \%$ ), and quality of life in terms of Karnofsky Performance Status (KPS) gained (RR 1.84, 95\%CI 1.54-2.19, $\mathrm{I}^{2}=0 \%$ ); alleviated grade 3 and 4 chemotherapy-related AEs for neutropenia (RR $0.33,95 \%$ CI $0.18-0.60, \mathrm{I}^{2}=0 \%$ ), nausea and vomiting ( $\mathrm{RR} 0.34,95 \%$ CI $0.17-0.67, \mathrm{I}^{2}=0 \%$ ) and neurotoxicity (RR $0.39,95 \% \mathrm{CI} 0.15-1.00, \mathrm{I}^{2}=0 \%$ ), compared to FOLFOX4 alone. The most frequently used herbs were Astragalus membranaceus, Panax ginseng, Atractylodes macrocephala, Poria cocos, Coix lachryma-jobi and Sophora flavescens. In experimental studies, each of these herbs has shown actions that could have contributed to improved tumor response.

Key words (6): colorectal cancer, FOLFOX, herbal medicine, tumor response, quality of life, metaanalysis

\author{
Abbreviations \\ ACRC: Advanced Colorectal Cancer \\ AEs: Adverse Events \\ BW: Body Weight \\ CAM: Complementary and Alternative Medicine \\ CNKI: China Academic Journals \\ CQVIP: Chinese Science and Technology Journals \\ CR: Complete Remission \\ CRC: Colorectal Cancer \\ FOLFOX: 5-Fluorouracil (5-FU) plus Leucovorin (LV) combined with Oxaliplatin
}

HMs: Herbal Medicines 
1

2

3

4

5

6

7

8

9

10

11

12

13

14

15

16

17

18

19

20

21

22

23

24

25

26

27

28

29

30

31

32

33

34

35

36

37

38

39

40

41

42

43

44

45

46

47

48

49

50

51

52

53

54

55

56

57

58

59

60

KPS: Karnofsky Performance Status

MD: Mean Difference

NCI-CTC: National Cancer Institute Common Toxicity Criteria

NK: Natural Killer

OS: Overall Survival

PD: Progressive Disease

PR: Partial Remission

QoL: Quality of Life

RCT: Randomized Controlled Trial

RD: Risk Difference

RECIST: Response Evaluation Criteria in Solid Tumors

RR: Risk Ratio

SD: Stable Disease

TNM: Tumor Node Metastasis

tRR: Tumor Response Rate

TTP: Time to Progression

WHO: World Health Organisation 


\section{Introduction}

Complementary and alternative medicine (CAM) use is common in cancer patients and more than $50 \%$ of patients use one or more type of CAM after the diagnosis (Vapiwala et al., 2006), mostly with the aim of improving health and well-being, boosting the immune system and controlling symptoms associated with the disease and treatments (Mansky and Wallerstedt, 2006). In a review of studies of CAM usage by colorectal cancer (CRC) patients in Western countries, Sewitch et al 2010 reported up to $75 \%$ prevalence of CAM use and herbal medicines (HM) were used by $48.7 \%$ of CRC patients in a European survey (Sewitch and Rajput, 2010). An estimated 1.5 billion people use Chinese HM worldwide (Dobos et al., 2005). In cancer therapy, Chinese HM has been reported to alleviate adverse events (AEs) induced by conventional cancer therapy and improve patient's quality of life (QoL) (Molassiotis et al., 2009), enhance cellular immunity of cancer patients receiving chemotherapy/radiotherapy (Zhuang et al., 2009), reduce cancer pain (Xu et al., 2007), relieve cancer related fatigue (Jeong et al., 2010), and improve anorexia and cachexia (Lee and Lee, 2010). Metaanalyses of clinical studies have demonstrated the addition of Chinese HMs to conventional therapy appears to improve tumour response and prolong survival in liver cancer (Shu et al., 2005) and in lung cancer (McCulloch et al., 2006)

Experimental studies have demonstrated that bio-active components in a number of single HMs and multi-herb formulae possess anti-cancer potential. In separate reviews, researchers explored the anticancer mechanisms of Chinese HMs and summarized these as multi-action and multi-targeted (Han and $\mathrm{Li}, 2009$; Parekh et al., 2009). The actions of HMs include anti-proliferative activity in cancer cells and induction of tumor cell apoptosis (Auyeung and Ko, 2010; Guo et al., 2013; Nguyen et al., 2013; Tin et al., 2007; Wang et al., 2009a); tumour angiogenesis suppression (Jeong et al., 2011; Law et al., 2012; Wang et al., 2009b); telomerase activity inhibition (Yu et al., 2006); immune function regulation (Gong, 2010); reversal of multiple drug resistance (Huang et al., 2011; Wang et al., 2007; Zhang et al., 2011); enhancing the cytotoxicity of the chemotherapy regimen (Cao et al., 2012; Tin et al., 2007); and management of chemotherapy side effects (Chen et al. 2009; Zhu et al 2007).

The FOLFOX regimen refers to 5-Fluorouracil (5-FU) plus Leucovorin (LV) combined with Oxaliplatin. It is a standard first line combination chemotherapy setting for advanced CRC (ACRC) (Lee and Chu, 2007; Prescrire Editorial Staff, 2010). A number of modalities of FOLFOX regimens, which consist of varying doses and schedules of 5-FU, LV and Oxaliplatin, have been studied in palliative settings. Of these, FOLFOX4 has been the most widely investigated (Waddell and Solimando, 2005). FOLFOX4 comprises a 2-hour infusion of LV (200 mg/ m²/d), followed by a 5-FU bolus $\left(400 \mathrm{mg} / \mathrm{m}^{2} / \mathrm{d}\right)$ and a 22 -hour infusion $\left(600 \mathrm{mg} / \mathrm{m}^{2} / \mathrm{d}\right)$ for 2 consecutive days every 2 weeks, together with Oxaliplatin $85 \mathrm{mg} / \mathrm{m}^{2}$ as a 2-hour infusion on day 1. It is used in conjunction with anti- 
nausea medications. The regimen is repeated every 14 days until disease progression or unacceptable toxicities force cessation (De Gramont et al., 2000).

FOLFOX4 has good evidence of efficacy for ACRC and is widely used but there are still AEs and these remain a major reason for discontinuation (Raftery and Goldberg, 2010). Consequently, clinicians may add HMs to the chemotherapy with the aim of reducing AEs and improving clinical outcomes (Saif et al., 2010). Systematic reviews of Chinese HMs in CRC treatment found that Chinese HM as an adjuvant treatment during chemotherapy for CRC prolonged 1 year and 3 year survival time, improved QoL, and reduced the incidence of chemotherapy-related AEs such as vomiting and nausea, diarrhoea, and leukopenia (Liu and Zhu, 2009; Wu et al., 2005; Zhong et al., 2012). However, these studies included various stages of CRC and various chemotherapy regimens. One systematic review that focussed on randomized or quasi-randomized controlled trials of Chinese HMs for ACRC using a variety of chemotherapy regimens found the addition of the HMs reduced mortality rate, improved 1 year and 3 year survival rate and QoL but the addition of the HMs did not benefit tumor response rate (tRR) (Guo et al., 2012).

This reviews focuses on HMs as adjuvants to FOLFOX4 in the treatment of ACRC. It includes randomized controlled trials (RCTs) published in medical journals and aims to determine which, if any, HMs demonstrate evidence of efficacy and safety in the treatment of ACRC and/or the management of the side effects of FOLFOX4 and to identify which HMs could have beneficial effects in ACRC.

\section{Method}

Searches were conducted of PubMed, Cochrane CENTRAL, CINAHL, Science Direct, PsycINFO, China Academic Journals (CNKI) and Chinese Science and Technology Journals (CQVIP) from their inceptions to December 2012. Three groups of search terms were used: 1. Disorder: colorectal cancer and related terms; 2. Intervention: herbal medicine, complementary medicine, Chinese medicine and related terms; and 3. Study type: controlled trial, randomised and related terms, with modifications according to the individual database. Full lists of search terms are available on request. Results were downloaded to Endnote libraries and combined. Reference lists in review articles and clinical studies were also searched.

Included studies were RCTs that employed FOLFOX4 combined with an HM intervention in the test arm and FOLFOX4 in the control arm, regardless of blinding with no restrictions on language or publication year. Participants were aged 18 to 80 years and had been pathologically diagnosed with ACRC that was either metastatic or regionally advanced, with Tumor Node Metastasis (TNM) stage IV, so curative surgical resection was unlikely to be carried out. Test interventions were HMs used 
singly or in combination, in any form including extracts and by any administration route. Only studies that provided data on at least one CRC-related primary or secondary outcome measure were included. Outcome measures could include tRR, survival, QoL, immune function and/or AEs.

Data extraction and Risk of Bias assessments were conducted by two reviewers independently (MC \& IZ) with mediation by AZ or BM. Data were extracted using pre-designed data collection forms. The validity of the outcomes of the included studies was assessed using the Cochrane Risk of Bias assessment method which includes the following categories of bias: selection bias, performance bias, detection bias, attrition bias, and reporting bias. The approach was according to the Cochrane Handbook version 5.1.0 (Higgins et al., 2011). Each domain was labelled 'low risk' or 'high risk' or 'unclear risk', with the last category indicating that there was insufficient information to judge the potential for bias.

Review Manager (RevMan) 5.1 was used for meta-analysis. Methods were based on Cochrane Handbook 5.1.0. Risk Ratio (RR) or Mean Difference (MD) with $95 \%$ confidence intervals ( $95 \%$ CI) using fixed or random-effect models depending upon heterogeneity were used. Risk Difference (RD) was calculated and presented as the percentage difference between the RRs of the test and control groups. The proportion of heterogeneity was measured using $\mathrm{I}^{2}$. It was defined as substantial heterogeneity if $\mathrm{I}^{2}$ was more than $50 \%$. In such cases sensitivity tests were done. When the same outcome was reported by more than 10 studies, publication bias was assessed using a funnel plot (Higgins et al., 2011).

\section{Results}

Database searches located 1,927 potentially relevant citations and 37 studies were identified by checking reference lists and print journals. Following screening, 68 studies were considered. These included nine studies that compared HM with placebo, no treatment, or chemotherapy and 58 that compared the combination of HM plus a non-FOLFOX4 chemotherapy regimen with the chemotherapy alone. Thirteen studies (Ding et al., 2010; Fang and Li, 2008; Li et al., 2007b; Li et al., 2007c; Qiu, 2011; Wu G et al., 2010; Xu and Wang, 2010; Yang, 2008; Zeng et al., 2009; Zeng et al., 2008; Zhang et al., 2008; Zhang et al., 2010a; Zhang et al., 2010b) that investigated a combination of HM plus FOLFOX4 versus FOLFOX4 for ACRC were included in this review (Fig 1).

The 13 studies enrolled 940 assessable in-patient participants with 486 participants in the test groups and 454 participants in the control groups. All studies were conducted in China and published in Chinese medical journals from 2007 to 2011. Participant characteristics, interventions and outcome measurements are summarized in Table 1. 
Twelve different test interventions were used. Seven studies employed commercially available HM extracts. Kang'ai Injection was used in two studies. Compound Kushen injection, Ginsenoside Rg3 capsules, Aidi injection, Guben Xiaoliu Capsule and Javanica oil injection were each used in one study. Six studies used multi-herbal decoctions. In total, 58 different herbs and/or their extracts were used, with the six most frequent being:

Huang qi Astragalus membranaceus (Fisch.) Bge. root (7 studies) (Li et al., 2007b; Li et al., 2007c; Qiu, 2011; Yang, 2008; Zeng et al., 2008; Zhang et al., 2008; Zhang et al., 2010b);

Yi yi ren Coix lachryma-jobi L. seed (6 studies) (Li et al., 2007c; Wu et al., 2010; Xu and Wang, 2010; Zeng et al., 2008; Zhang et al., 2008; Zhang et al., 2010a);

Ren shen Panax ginseng C.A.Mey. root (5 studies) (Li et al., 2007b; Qiu, 2011; Yang, 2008; Zeng et al., 2009; Zhang et al., 2010a);

Ku shen Sophora flavescens Ait. root (5 studies) (Ding et al., 2010; Qiu, 2011; Yang, 2008; Zeng et al., 2008; Zhang et al., 2008);

Bai zhu Atractylodes macrocephala Koidz. root (5 studies) (Li et al., 2007c; Xu and Wang, 2010; Zeng et al., 2008; Zhang et al., 2008; Zhang et al., 2010b); and

Fu ling Poria cocos (Schw) Wolf sclerotium (4 studies) (Li et al., 2007c; Wu et al., 2010; Xu and Wang, 2010; Zhang et al., 2008).

\section{Methodological assessment}

All studies claimed to be randomized. Five studies (38.4\%) stated a proper method of generation of randomization sequence, so the risk of bias was judged as 'low' in these studies (Ding et al., 2010; Fang and Li, 2008; Li et al., 2007c; Wu et al., 2010; Zhang et al., 2010a). The other eight studies did not describe the randomization method and were judged as 'unclear'. None of the studies described the procedure of allocation concealment. Therefore, an 'unclear' judgement was made (Table 1).

A placebo group was not used in any of the studies and none reported a method of blinding. There is generally no blinding in oncology trials (Hind D et al., 2008), so we expect that all trials were open to participants and personnel. Thus, there was possible performance bias and detection bias for subjective outcomes such as QoL and AEs. Therefore a 'high' risk of bias was judged for subjective outcomes. Radiologists and laboratory pathologists measured the objective outcomes, such as tumor response and laboratory tests. Outcome data on survival rate and time to progression was obtained from medical records. These kinds of data were unlikely to have been influenced by lack of blinding, so we judged 'low risk' of detection bias for these outcomes. Three studies reported the numbers of participants who dropped out during the trial or were lost to follow-up (Ding et al., 2010; Li et al., 2007c; Zhang et al., 2010b) but no reasons were given and these missing data were not treated as 'intent to treat'. So, these were judged as 'high risk' of attrition bias. Studies that had the same 
numbers of participants at the inception as at the outcome reports were judged as 'low risk' of attrition bias. None of the studies had published study protocols. When the study objectives and outcome measures were stated in the study method section and when all outcomes were reported in the results section, the study was judged as 'low risk' of reporting bias (Table 1).

Twelve studies reported on tRR so a Funnel Plot was used to assess publication bias (Fig. 2). The symmetry of the Funnel Plot suggests the risk of publication bias was low for these studies.

Meta-analysis results

Meta-analyses were performed for each of the following outcomes. The numerical data are presented in Table 2.

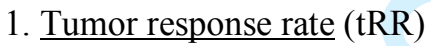

Twelve studies reported tRR. Ten evaluated tRR using the WHO solid tumor response criteria (Miller et al., 1981) as follows: complete remission (CR), partial remission (PR), stable disease (SD), and progressive disease (PD). The other two studies (Qiu, 2011; Zhang et al., 2010b) used the RECIST criteria, which use similar categories (Park et al., 2003), so data could be pooled for all studies. CR plus PR was defined as 'clinically effective' so these data were included in meta-analyses. When the Risk Ratio (RR) is more than 1 (IV model, Fixed, 95\% CI) it favours the test group. Positive outcomes favour test groups.

The tRR ranged from $30 \%$ to $54.1 \%$ for the test groups and from $20 \%$ to $46.6 \%$ for the control groups in the 12 studies (880 participants)(Fang and Li, 2008; Li et al., 2007b; Li et al., 2007c; Qiu, 2011; Wu G et al., 2010; Xu and Wang, 2010; Yang, 2008; Zeng et al., 2009; Zeng et al., 2008; Zhang et al., 2008; Zhang et al., 2010a; Zhang et al., 2010b). There was a significant improvement in tRR for HMs plus FOLFOX4 (test groups) compared to FOLFOX4 alone (Table 2). The pooled tRR in the test groups was elevated to $44.1 \%$ (RD 9.2\%). For the two studies of Kang'ai Injection, the RD was 3.0\% but there was no significant difference between groups. The total numbers of complete remissions (CRs) in the test and control groups were 19 and 8 patients respectively but this difference was not significant (RD 2.8\%). The tRR data included 234 (24.9\%) participants who were previously treated with chemotherapy for ACRC but separate results were reported for only 126 of these. Previously treated ACRC patients have been found to be less responsive to current first-line settings of chemotherapy (Giantonio et al., 2007). When the subgroups of previously treated ( 2 studies) and previously untreated ( 3 studies) patients were analysed, the RD of the pooled tRR was $8.7 \%$ in each group but there was no significant difference between test and control groups (Table 2). 


\section{Overall survival (OS) and time to progression (TTP)}

Time to event data for OS was treated as dichotomous data with the number of surviving participants in each treatment group at one year as the event number entry and the total number of participants in each group as the total number entry (Higgins et al., 2011). Three studies reported one year OS. There was a significant difference in favour of the test groups (RD 20.2\%) (Table 2). No long-term (two years or more) OS data were reported.

Median OS and median TTP were each reported in three studies. Median OS was 12.5 months for the test group versus 10.8 months for the control group in one study (Li et al., 2007b); 13.6 months (test) versus 10.2 (control) in another study (Zhang et al., 2010b); and 19.8 months (test) versus 18.6 (control) in Ding et al (2010). Median TTP was 8.1 months (test) versus 6.9 months (control) in Zhang et al (2010b), 9.2 (test) versus 8.7 months (control) in Ding et al (2010), and 16.5 months (test) versus 10.2 months (control) in Xu et al (2010). Meta-analysis was not feasible.

\section{Quality of life (QoL) and body weight (BW)}

Ten studies used Karnofsky Performance Status (KPS) to measure QoL changes before and after treatment (Li et al., 2007b; Li et al., 2007c; Qiu, 2011; Wu G et al., 2010; Xu and Wang, 2010; Zeng et al., 2009; Zeng et al., 2008; Zhang et al., 2008; Zhang et al., 2010a; Zhang et al., 2010b). KPS is a single dimension scale that provides a global measurement of patient physical function. Its reliability and validity have been investigated and verified (Granda-Cameron C et al., 2008). Nine studies defined a KPS score gain of $\geq 10$ points as 'improved'; a decline of $\geq 10$ points as 'worse'; and changes of less than 10 points as 'stable'. Three studies (Yang, 2008; Zeng et al., 2009; Zhang et al., $2010 \mathrm{~b}$ ) included body weight (BW) measurement. BW gain $\geq 1.0 \mathrm{~kg}$ was defined as 'improved' and weight loss of $\geq 1.0 \mathrm{~kg}$ was defined as 'worse'. Changes in the range between 'improved' and 'worse' were defined as 'stable'.

Clinical effectiveness was defined as 'improved' for KPS and as 'improved' for BW. To minimize bias resulting from small changes in scores, the meta-analyses only included patients who recorded a KPS score that was 10 or more points higher after the intervention compared to prior to the intervention and patients who had gained $1 \mathrm{~kg}$ or more. Patients who achieved a stable KPS score and/or stable BW after the intervention were excluded from the analyses.

The KPS improvement was significantly greater in the test groups based on 9 studies (RD 28.8\%) (Table 2). In Wu et al (2010), KPS was presented as mean plus standard deviation (SD). There was no statistically significant difference before and after the treatment in the test group (MD 0.44, 95\% CI 3.94 to $4.82, p=0.84$ ) but there was a significant decline after treatment in the control group (MD 
$13.40,95 \%$ CI 7.22 to $19.58, p<0.0001$ ), so the mean KPS after treatment was significantly higher in the test group, indicating a relative improvement in the test group (Table 2).

Yang (2008) reported Su Ying's QoL Questionnaire which comprised 12 items which are scored 5-1 according to increase in severity, so the more severe the symptoms the lower the score. In the test group, the total score was not significantly different before and after the treatment (MD $-1.57,95 \%$ CI -3.44 to $0.30, p=0.10$ ) but it significantly decreased in the control group after treatment (MD 2.70, $95 \%$ CI 1.34 to $4.06, p<0.0001)$. The between-groups scores after treatment were significantly different in favor of the test group (Table 2). There was a significant difference in body weight improvement in favour of the test group based on three studies (RD 18.9\%) (Table 2).

\section{Alleviation of adverse events associated with chemotherapy}

All 13 studies reported that the HMs alleviated chemotherapy toxicity. The criteria for grading acute and subacute toxicity recommended by WHO (Miller et al., 1981) were used in ten studies and three studies (Qiu, 2011; Yang, 2008; Zhang et al., 2010a) used the National Cancer Institute Common Toxicity Criteria (NCI-CTC) (National Cancer Institute, 1999). These systems use similar grading criteria so we followed Hind (2008) and pooled data where possible (Hind D et al., 2008). Zhang et al reported events as gastrointestinal reactions or myelosuppression (Zhang et al., 2008), and Zeng et al reported toxicity events as totals (all grades) (Zeng et al., 2009). Therefore, these two studies were not included in the meta-analysis.

Most of the AEs were mild (grades 1-2). The three most commonly reported AEs were nausea and vomiting, neutropenia, and neurotoxicity. The meta-analyses included toxic events at grades 3 and 4 only (i.e. severe toxicity) (Table 2). The pooled grade 3 and 4 events for neutropenia ( $n=10, R D$ 8.7\%), nausea and vomiting ( $\mathrm{n}=9$, RD 9.5\%), and neurotoxicity ( $\mathrm{n}=7, \mathrm{RD} 3.8 \%$ ) were significantly fewer in the test groups. For the Kang'ai Injection sub-group $(n=2)$, significant reductions were found for neutropenia (RD 17.8\%) and nausea and vomiting events (RD 15.8\%). No significant difference between groups was found for the pooled grade 3 and 4 events for: diarrhoea ( 5 studies, RD 2.4\%), anaemia (3 studies, RD 2.9\%), stomatitis (2 studies, RD 2.3\%), thrombocytopenia (1 study), or constipation (1 study). Adverse events specific to the HMs were not reported in any of the 13 studies.

\section{Effect on immune function}

Four studies reported effects on immune function, in terms of the percentage of T-lymphocyte subsets and Natural Killer (NK) cell activity in serum. One study reported benefits for T-cells and NK cells but data were as difference scores, so these could not be included in pooling (Zeng et al., 2009). There 
was a significant improvement in the pooled data for CD3+ cells (Wu G et al., 2010), and Ratio CD4+/CD8+ cells (Ding et al., 2010; Zhang et al., 2010a) (Table 2). For CD4+, CD8+ cells and NK cells, there were benefits reported in some studies but the pooled results were too heterogeneous to be meaningful.

\section{Discussion}

All thirteen studies included in this review were published after 2007 and all employed FOLFOX4 as a single regimen. Since this is currently the most commonly used first-line chemotherapy regimen for $\mathrm{ACRC}$, the results of this review are of direct clinical relevance.

Internationally recognized measurement systems were used in all included studies, including the TNM staging system, WHO criteria for solid tumor response and grading of acute and subacute toxicity, and the KPS scoring system. Participants' age was in the range 48-60 in nine studies and one study enrolled participants whose mean age was 72.7 years (Li et al., 2007c). From an international perspective, the majority of the cohort was younger than the general population of CRC patients whose median age is over 70. A tendency for trial participants to be younger than the average CRC patient has been found in other ACRC trials but younger patients did not appear to respond better or experience less toxicity than older patients (Hind D et al., 2008), so this difference was judged as not likely to affect the generalizability of results. Overall, the heterogeneity of meta-analyses was low for the clinical outcome measures.

The pooled data indicate the addition of the HMs significantly improved tRR when compared to FOLFOX4 alone (Table 2). In the sub-group analysis of tRR for previously treated and untreated ACRC participants the results showed a similar benefit for the HM in both groups (RD $8.7 \%$ in each) but this did not reach significance (Table 2). It is possible that the small number of participants in these sub-groups meant there was insufficient statistical power to detect a difference. The additional HM intervention improved CR (RD 2.8\%) but it was not statistically significant. It is notable that FOLFOX4 itself has not yielded high CRs in ACRC (Cassidy et al., 2008; De Gramont et al., 2000; Goldberg et al., 2004; Goldberg et al., 2006). Overall, these results suggested that the HMs conferred an additional benefit to tRR when combined with FOLFOX4 for ACRC. But these results need to be verified by a large scale clinical trial.

The review by Zhong et al (2012) included 20 studies that used a number of chemotherapy regimens for a range of CRC stages including two studies that used FOLFOX 4. These two studies were not included in the present meta-analysis since they did not use FOLFOX 4 alone for ACRC, so there is no overlap between these two reviews. Zhong et al (2012) reported benefits for tRR, survival, KPS, immune response and chemotherapy AEs. In contrast, the review of 20 RCTs for ACRC by Guo et al 
(2012) found HM did not benefit tRR. Six of the studies in the present review were also included in Guo et al (2012). The likely reason for the different result is Guo et al (2012) analyzed tRR separately for each study. Since each study was small, there was insufficient statistical power to detect an effect. In the present review, the focus on a single chemotherapeutic intervention enabled more meaningful meta-analyses, as did the separate analyses of tRR for previously treated and untreated ACRC participants.

One year-OS was greater in the HM plus FOLFOX4 groups compared to FOLFOX4 alone (Table 2). Median OS in the FOLFOX4 plus HM group ranged from 12.5 to 19.8 months (Ding et al., 2010; Li et al., 2007b; Zhang et al., 2010b) and the median TTP ranged from 8.1 to 16.5 months (Ding et al., 2010; Xu and Wang, 2010; Zhang et al., 2010b). So the addition of the HM appeared to modestly improve both median OS and TTP but meta-analyses were not feasible.

\section{Other outcomes}

Participants in the test groups were more likely to show a KPS improvement than in the control groups (RD 28.8\%). For chemotherapy-related AEs, significant reductions were found in the test groups for grade 3 and 4 neutropenia (T: $3.9 \%$ vs C: $12.6 \%$ ), nausea and vomiting ( $\mathrm{T}: 3.0 \%$ vs $\mathrm{C}$ : $12.5 \%$ ) and neurotoxicity (T: $2.2 \%$ vs $\mathrm{C}: 6.0 \%$ ) (Table 2 ). These findings were generally consistent with earlier reviews of HM adjuvant to chemotherapy for CRC (Liu and Zhu, 2009; Wu et al., 2005; Zhong et al., 2012).

The results for T-lymphocyte subsets suggest that some HMs may have immune enhancing effects but these data were only available for a few studies and there was substantial heterogeneity in some of the meta-analyses (Table 2). It is notable that the following HMs that were used in these studies, Astragalus membranaceous, Panax ginseng, Atractylodes macrocephala, Poria cocos and Coix lachryma-jobi, have been reported to have immunomodulatory effects (Gong, 2010; Yang et al., 2002; Yang et al., 2011).

\section{Comparison with other studies of FOLFOX4}

The improvement in tRR of $20.0 \%$ to $46.6 \%$ (average $34.9 \%$ ) for the control groups in 12 studies was consistent with the results of a review by Lu et al (2010) that pooled 27 clinical studies of FOLFOX4 for ACRC conducted in China (879 participants), none of which involved a comparison with HM (Lu et al., 2010). The review by Lu et al found the following tRRs: total 26.10-57.14\% (27 studies); previously untreated patients $30.8-65.0 \%$ (12 studies); and previously treated patients $16.6-47.6 \%$ (12 studies). In this review, the pooled tRRs of $34.9 \%$ for all control group participants, $42.4 \%$ for previously untreated participants, and $21.0 \%$ for previously treated participants all fell within these ranges, so the results for the control groups in this review are broadly consistent with non-HM studies 
conducted in China on FOLFOX4. In the control groups in this review, the median OS was 10.2-18.6 months and the TTP was 6.9-10.2 months, which were similar to the ranges found in the review by Lu et al (OS 9.0-17.7 months, TTP 5.47-9.00 months) (Lu et al., 2010).

We noticed the average tRR (34.9\%) in the control groups in this review and in the review of Chinese FOLFOX4 studies (Lu et al., 2010) were relatively low compared to large international trials (Cassidy et al., 2008; De Gramont et al., 2000; Goldberg et al., 2004; Goldberg et al., 2006) in which the tRRs were in the range $45.0-58.5 \%$. These international trials only included previously untreated ACRC, whereas in this review the trial participants were both previously treated and untreated ACRC participants and there were no second line treatments in the Chinese trials. Both these factors could adversely affect the outcomes for tRR (De Gramont et al., 2000; Giantonio et al., 2007).

In the included studies, the most common FOLFOX4-related grade 3 and 4 AEs were neutropenia, nausea and vomiting, diarrhoea, and neurotoxicity, which are the same as in the international studies (Cassidy et al., 2008; De Gramont et al., 2000; Goldberg et al., 2004; Goldberg et al., 2006). However, the incidence rates for grade 3-4 neutropenia, neurotoxicity and diarrhoea in the pooled control group data were less than in the international studies. A likely reason for this difference is the relatively short duration of treatment in the studies in this review, since neutropenia and neurotoxicity tend to become more severe the longer the chemotherapy continues (Boisdron-Celle et al., 2002; De Gramont et al., 2000). The grade 3-4 nausea and vomiting rate was comparable to the international studies. This may due to the preventive use of anti-emetic drugs and dose modification in FOLFOX4 protocols which enable control of the severity of nausea and vomiting even with longer treatment.

\section{Limitations to this systematic review}

In interpreting the findings of this systematic review a number of factors need to be considered including methodological issues, trial duration, the nature and size of study samples, and variation in the HMs used. All studies claimed to be randomized but only five stated an appropriate method of sequence generation and none provided information on allocation concealment procedures, so there was potential for selection bias. Lack of blinding increases the risk of bias for subjective outcomes such as KPS and AEs such as nausea, so the results for these outcomes should be considered less reliable than for more objective measures such as tRR and OS. Three studies did not report reasons for dropouts or loss to follow-up. Methodological issues of these types have been found in trials of both conventional medicine and HM conducted in China (Wu et al., 2009). Clinical trial reporting needs to be clear, complete and transparent (Moher et al., 2010), so there is a pressing need for improvements in the conduct of clinical trials in China and for proper reporting of methods and results in Chinese journals. 
Most the studies were relatively small and small trials appear to overestimate true effects (Higgins et al., 2011). Some trials appear to have included both previously treated and untreated participants without reporting separate results for these two groups who could be expected to show differential responses to interventions. Other issues are quality control of the medicines prepared by the investigators' hospitals and the use of test medicines that comprise multiple ingredients which may vary in quality from batch to batch and may be affected by decoction conditions. These factors limit the comparability of studies. While there was no apparent publication bias based on the Funnel Plot for tRR, there may have been bias in favor of positive trials for other outcomes.

How these HMs might work

Except for Kang'ai injection, which was tested in two studies, different multi-herb decoctions or manufactured products were tested in each study. Therefore, on the basis of the clinical trial results alone, it is difficult to determine which individual herbs could have contributed to the reported effects. The main rationale for combining Chinese HMs with chemotherapy was the alleviation of AEs. Of the six most commonly used herbs in these RCTs, Astragalus, Ginseng, Atractylodes, Poria and Coix are traditionally used for fatigue, poor appetite, diarrhoea and other gastrointestinal disorders (Bensky et al., 2004) and each of these herbs has been reported to have immunomodulatory effects (Gong, 2010; Shergis et al., 2012; Yang et al., 2011). These actions may at least partially account for the reported improvements in AEs. In addition, recent experimental research into each of the six herbs used most frequently in the 13 studies indicates that each has effects that may contribute to the suppression of tumor growth. The findings of these studies are discussed below.

Astragalus polysaccharides have been shown to have anti-proliferative effects in cell-line studies (Zong et al., 2012). Astragalus saponins inhibited proliferation in a human colorectal cancer HT-29 cell line regardless of the 553 status, demonstrated tumor suppressive effects in a nude mice xenograft model, enhanced the cytotoxic effect of 5-FU (Tin et al., 2007) and have demonstrated antiangiogenic effects (Law et al., 2012). Astragalus flavonoids have also been reported to have proapoptopic effects in colon cancer HCT-116 cells (Auyeung and Ko, 2010).

A number of studies have found ginsenosides and ginseng polysaccharides to have anti-proliferative and pro-apoptopic effects (Nag et al., 2012; Zong et al., 2012). The ginsenoside Rg3 inhibited growth of tumours in-vivo in HCT-116 cells (He et al., 2011) and has shown anti-angiogenic activities (Wang et al., 2009b). Also, the ginseng saponin metabolite, compound $\mathrm{K}$, has been reported to inhibit metastatic growth in hepatocellular carcinoma both in-vitro and in-vivo (Ming et al., 2011).

Coix seed has a long history as an anti-cancer agent in China and has been developed into an injectable product (Kanglaite Coix oil extract) (Li, 2007; Woo et al., 2007). Coix extracts have been 
shown to have anti-inflammatory and anti-carcinogenic effects in animal models of CRC (Chung et al., 2010; Li et al., 2011). Polysaccharides from Poria cocos appear to potentiate immune response by up-regulating immune stimulators and down-regulating immune suppressors and have shown antitumor activity in various cancer cell lines by suppressing tumor angiogenesis (Rios, 2011).

Compounds derived from Atractylodes have shown bio-activity in-vitro. Anti-inflammatory effects have been reported for atractylenolide I and atractylenolide III (Li et al., 2007a) and atractylenolide II inhibited proliferation of B16 cells, induced G1 cell-cycle arrest and induced apoptosis (Ye et al., 2011). In mouse splenocytes, Atractylodes glycoproteins stimulated both Th1 and Th2 lymphocyte proliferation with a greater effect on Th1 lymphocytes (Lee et al., 2007). In an RCT of cachetic cancer patients $(\mathrm{n}=64)$, the administration of a lactone from Atractylodes improved mid-arm muscle circumference, reduced the serum levels of interleukin-1 (IL-1) and tumor necrosis factor alpha (TNFalpha) and reduced urine proteolysis-inducing factors (PIF) (Liu et al., 2005).

The alkaloids matrine and oxymatrine found in Sophora root have been developed into anti-cancer agents in China and Sophora flavonoids appear to have antitumor activity (Sun et al., 2012), for example, sophoflavescenol has shown cytotoxicity in a number of cancer cell lines as well as having antioxidant, anti-inflammatory and apoptotic activities (Jung et al., 2011).

While it appears possible that at least some of the HMs used in these studies may have contributed to tumor response directly, it is also possible that this effect was indirect via alleviating AEs and thereby enabling patients to better tolerate the chemotherapy. Further research is needed to investigate these issues.

\section{Conclusion}

The meta-analysis results suggest the addition of these HMs to a FOLFOX4 regimen in ACRC increases tumor response rate (tRR) and one year survival but evidence is lacking for longer term effects. The addition of the HM interventions appear to have improved quality of life and reduced the incidence of severe neutropenia, nausea, vomiting, and neurotoxicity associated with the chemotherapy. Experimental studies on the actions of the most commonly used herbs suggest possible anti-tumor activity which may at least partially explain these results. However, methodological weaknesses were evident in each of the RCTs so any conclusions must be tentative. Further investigation is required using sufficiently powered, rigorously designed RCTs over longer durations. 


\section{References}

Auyeung KK, and Ko JK. 2010. Novel herbal flavonoids promote apoptosis but differentially induce cell cycle arrest in human colon cancer cell. Invest New Drugs 28: 1-13.

Bensky D, Clavey S, and Stoger E. 2004. Chinese Herbal Medicine: Materia medica. Eastland Press, Seattle.

Boisdron-Celle M, Craipeau MC, Brienza S, et al. 2002. Influence of oxaliplatin on 5-fluorouracil plasma clearance and clinical consequences. Cancer Chem Pharm 49: 235-243.

Cao Z, Liao L, Chen X, et al. 2012. Enhancement of Antitumor Activity of Low-Dose 5-Fluorouracil by Combination With Fuzheng-Yiliu Granules in Hepatoma 22 Tumor-Bearing Mice. Integr Cancer Ther 10.1177/1534735412450514.

Cassidy J, Clarke S, Diaz-Rubio E, et al. 2008. Randomized phase III study of capecitabine plus oxaliplatin compared with fluorouracil/folinic acid plus oxaliplatin as first-line therapy for metastatic colorectal cancer. J Clin Oncol 26: 2006-2012.

Chen Y, Zhu B, Zhang L, et al. 2009. Experimental study of the bone marrow protective effect of a traditional Chinese compound preparation. Phytotherapy Research 23: 823-826.

Chung CP, Hsu HY, Huang DW, et al. 2010. Ethyl acetate fraction of adlay bran ethanolic extract inhibits oncogene expression and suppresses DMH-induced preneoplastic lesions of the colon in F344 rats through an anti-inflammatory pathway. J Agric Food Chem 58: 7616-7623.

De Gramont A, Figer A, Seymour M, et al. 2000. Leucovorin and fluorouracil with or without oxaliplatin as first-line treatment in advanced colorectal cancer. J Clin Oncol 18: 2938-2947.

Ding X, Xiao XY, Yang XY, et al. 2010. Clinical observation of compound Kushen injection combined with FOLFOX4 regime for patients with advanced colorectal cancer. China Oncology 860-863.

Dobos G, Tan L, Cohen M, et al. 2005. Are national quality standards for traditional Chinese herbal medicine sufficient?: Current governmental regulations for traditional Chinese herbal medicine in certain Western countries and China as the Eastern origin country. Complement Ther Med 13: 183-190.

Fang MZ, and Li M. 2008. The curative effect of the treatment for metastatic colorectal cancer by the FOLFOX4 scheme combining Javanica oil emulsion and the observation of adverse effects. Chinese Journal of Information on Traditional Chinese Medicine 15: 74-75.

Giantonio B, Catalano P, Meropol N, et al. 2007. Bevacizumab in combination with oxaliplatin, fluorouracil, and leucovorin (FOLFOX4) for previously treated metastatic colorectal cancer: results from the Eastern Cooperative Oncology Group Study E3200. J Clin Oncol 25: 15391544.

Goldberg R, Sargent D, Morton R, et al. 2004. A Randomized controlled trial of fluorouracil plus leucovorin, irinotecan, and oxaliplatin combinations in patients with previously untreated metastatic colorectal cancer. J Clin Oncol 22: 23-30.

Goldberg R, Sargent D, Morton R, et al. 2006. Randomized controlled trial of reduced-dose bolus fluorouracil plus leucovorin and irinotecan or infused fluorouracil plus leucovorin and oxaliplatin in patients with previously untreated metastatic colorectal cancer: a North American Intergroup Trial. J Clin Oncol 24: 3347-3353.

Gong T. 2010. Progress in Chinese medicine treatment of leucopenia after chemotherapy. Guiding Journal of Traditional Chinese Medicine and Pharmacy 16: 105-106.

Granda-Cameron C, Viola Sr, Lynch Mp, et al. 2008. Measuring patient-oriented outcomes in palliative care: functionality and quality of life. Clin J Oncol Nurs 12: 65-77.

Guo LD, Chen XJ, Hu YH, et al. 2013. Curcumin inhibits proliferation and induces apoptosis of human colorectal cancer cells by activating the mitochondria apoptotic pathway. Phytotherapy Research 27: 422-430.

Guo Z, Jia X, Liu JP, et al. 2012. Herbal medicines for advanced colorectal cancer. Cochrane Database Syst Rev 5: CD004653.

Han SY, and Li PP. 2009. Progress of research in antitumor mechanisms with Chinese medicine. Chin J Integr Med 15: 316-320. 
He BC, Gao JL, Luo X, et al. 2011. Ginsenoside Rg3 inhibits colorectal tumor growth through the down-regulation of Wnt/ß-catenin signaling. Int J Oncol 38: 437-445.

Higgins JPT, Green S, and (Editors). 2011. Cochrane Handbook for Systematic Reviews of Interventions Version 5.1.0 [updated March 2011], The Cochrane Collaboration.

Hind D, Tappenden P, Tumur I, et al. 2008. The use of irinotecan, oxaliplatin and raltitrexed for the treatment of advanced colorectal cancer: systematic review and economic evaluation. Health Technol Assess 12: 3-9, 11-162.

Huang F, Li S, Lu X, et al. 2011. Two glutathione S-transferase inhibitors from Radix Angelicae sinensis. Phytotherapy Research 25: 284-289.

Jeong JS, Ryu BH, Kim JS, et al. 2010. Bojungikki-tang for cancer-related fatigue: a pilot randomized clinical trial. Integr Cancer Ther 9: 331-338.

Jeong SJ, Koh W, Lee EO, et al. 2011. Antiangiogenic phytochemicals and medicinal herbs. Phytotherapy Research 25: 1-10.

Jung HA, Jin SE, Choi RJ, et al. 2011. Anti-tumorigenic activity of sophoflavescenol against Lewis lung carcinoma in vitro and in vivo. Arch Pharm Res 34: 2087-2099.

Law PC, Auyeung KK, Chan LY, et al. 2012. Astragalus saponins downregulate vascular endothelial growth factor under cobalt chloride-stimulated hypoxia in colon cancer cells. $B M C$ Complement Altern Med 12: 160.

Lee JC, Lee KY, Son YO, et al. 2007. Stimulating effects on mouse splenocytes of glycoproteins from the herbal medicine Atractylodes macrocephala Koidz. Phytomedicine 14: 390-395.

Lee JJ, and Chu E. 2007. An update on treatment advances for the first-line therapy of metastatic colorectal cancer. Cancer J 13: 276-281.

Lee JJ, and Lee JJ. 2010. A phase II study of an herbal decoction that includes Astragali radix for cancer-associated anorexia in patients with advanced cancer. Integr Cancer Ther 9: 24-31.

Li CQ, He LC, Dong HY, et al. 2007a. Screening for the anti-inflammatory activity of fractions and compounds from Atractylodes macrocephala koidz. J Ethnopharmacol 114: 212-217.

Li DP. 2007. Progress in pharmacodynamics and clinical studies of active components of Coix Seed (Semen Coicis) and its preparation - Kanglaite Injection (KLT). Traditional Chinese Drug Research \& Clinical Pharmacology: 778-782.

Li HJ, Dong L, and Fu SY. 2007b. Comparative study on treatment of advanced colorectal cancer by Aidi injection combined with FOLFOX4 regimen and by FOLFOX4 regimen alone. Chinese Journal of Integrated Traditional and Western Medicine 27: 1086-1089.

Li SC, Chen CM, Lin SH, et al. 2011. Effects of adlay bran and its ethanolic extract and residue on preneoplastic lesions of the colon in rats. J Sci Food Agric 91: 547-552.

Li YJ, Chen JZ, Huang WX, et al. 2007c. Treatment of Wenshen Jianpi Fang combination with chemotherapy for advanced colorectal cancer Fujian Journal Traditional Chinese Medicine 38: $13-14$.

Liu J, and Zhu Q. 2009. The reduction of adverse drug reaction incidences of colorectal cancer patients receiving Jianpi herbs combined with chemotherapy: a systematic review Chin J Evid-based Med 9: 802-808.

Liu Y, Ye F, Qiu GQ, et al. 2005. Effects of lactone I from Atractylodes macrocephala Koidz on cytokines and proteolysis-inducing factors in cachectic cancer patients. Academic Journal of The First Medical College of PLA 25: 1308-1311.

$\mathrm{Lu} \mathrm{XM,} \mathrm{Zhu} \mathrm{YJ,} \mathrm{Gu} \mathrm{Y,} \mathrm{et} \mathrm{al.} \mathrm{2010.} \mathrm{Chinese} \mathrm{reports} \mathrm{on} \mathrm{the} \mathrm{effect} \mathrm{and} \mathrm{safety} \mathrm{of} \mathrm{FOLFOX} \mathrm{or} \mathrm{FOLFIRI}$ for advanced colorectal cancer. Journal of Liaoning University of Traditional Chinese Medicine 12: 91-93.

Mansky PJ, and Wallerstedt DB. 2006. Complementary medicine in palliative care and cancer symptom management. Cancer $J$ 12: 425-431.

McCulloch M, See C, Shu XJ, et al. 2006. Astragalus-based Chinese herbs and platinum-based chemotherapy for advanced non-small-cell lung cancer: meta-analysis of randomized trials. $J$ Clin Oncol 24: 419-430.

Miller AB, Hoogstraten B, Staquet M, et al. 1981. Reporting results of cancer treatment. Cancer 47: 207-214. 
Ming Y, Chen Z, Chen L, et al. 2011. Ginsenoside compound K attenuates metastatic growth of hepatocellular carcinoma, which is associated with the translocation of nuclear factor-kappaB p65 and reduction of matrix metalloproteinase-2/9. Planta Med 77: 428-433.

Moher D, Hopewell S, Schulz KF, et al. 2010. CONSORT 2010 Explanation and Elaboration: updated guidelines for reporting parallel group randomised trials. BMJ $\mathbf{3 4 0}$.

Molassiotis A, Potrata B, and Cheng K. 2009. A systematic review of the effectiveness of Chinese herbal medication in symptom management and improvement of quality of life in adult cancer patients. Complement Ther Med 17: 92-120.

Nag SA, Qin JJ, Wang W, et al. 2012. Ginsenosides as Anticancer Agents: In vitro and in vivo Activities, Structure-Activity Relationships, and Molecular Mechanisms of Action. Front Pharmacol 3: 25.

Nguyen HT, Du GJ, Wang CZ, et al. 2013. Naphthoquinone components from alkanna tinctoria (1.) tausch show significant antiproliferative effects on human colorectal cancer cells. Phytotherapy Research 27: 66-70.

National Cancer Institute. 1999. Common Toxicity Criteria. Version 2.0 National Cancer Institute.

Parekh HS, Liu G, and Wei MQ. 2009. A new dawn for the use of traditional Chinese medicine in cancer therapy. Mol Cancer 8: 1-8.

Park JO, Lee SI, Song SY, et al. 2003. Measuring response in solid tumors: comparison of RECIST and WHO response criteria. Jpn J Clin Oncol 33: 533-537.

Prescrire Editorial Staff. 2010. Chemotherapy of metastatic colorectal cancer. Prescrire Int 19: 219224.

Qiu ZC. 2011. Kang'ai Injection combined with chemotherapy in treating advanced colorectal cancer. Shaanxi Journal of Traditional Chinese Medicine 32: 3-4.

Raftery L, and Goldberg RM. 2010. Optimal delivery of cytotoxic chemotherapy for colon cancer. Cancer J 16: 214-219.

Rios JL. 2011. Chemical constituents and pharmacological properties of Poria cocos. Planta Med 77: 681-691.

Saif M, Lansigan F, Ruta S, et al. 2010. Phase I study of the botanical formulation PHY906 with capecitabine in advanced pancreatic and other gastrointestinal malignancies. Phytomedicine 17: 161-169.

Sewitch M, and Rajput Y. 2010. A literature review of complementary and alternative medicine use by colorectal cancer patients. Complement Ther Clin Pract 16: 52-56.

Shergis JL, Zhang AL, Zhou W, et al. 2012. Panax ginseng in randomised controlled trials: a systematic review. Phytotherapy Research 27: 949-965

Shu X, Mcculloch M, Xiao H, et al. 2005. Chinese herbal medicine and chemotherapy in the treatment of hepatocellular carcinoma: a meta-analysis of randomized controlled trials. Integr Cancer Ther 4: 219-229.

Sun M, Cao H, Sun L, et al. 2012. Antitumor activities of kushen: literature review. Evid Based Complement Alternat Med 2012: 373219.

Tin MM, Cho CH, Chan K, et al. 2007. Astragalus saponins induce growth inhibition and apoptosis in human colon cancer cells and tumor xenograft. Carcinogenesis 28: 1347-1355.

Vapiwala N, Mick R, Hampshire MK, et al. 2006. Patient initiation of complementary and alternative medical therapies (CAM) following cancer diagnosis. Cancer $J$ 12: 467-474.

Waddell JA, and Solimando DA. 2005. Leucovorin, Fluorouracil, and Oxaliplatin (FOLFOX 6 and 7) regimens for colorectal cancer. Hospital Pharmacy 40: 662-670.

Wang CZ, Xie JT, Fishbein A, et al. 2009a. Antiproliferative effects of different plant parts of Panax notoginseng on SW480 human colorectal cancer cells. Phytotherapy Research 23: 6-13.

Wang J, Xia Y, Wang H, et al. 2007. Chinese herbs of Shenghe Powder reverse multidrug resistance of gastric carcinoma SGC-7901. Integr Cancer Ther 6: 400-404.

Wang X, Zheng YL, Li K, et al. 2009b. The effects of ginsenosides Rg3 on the expressions of VEGF and KDR in human lung squamous cancer cells. Journal of Chinese medicinal materials 32: 1708-1710.

Woo JH, Li D, Wilsbach K, et al. 2007. Coix seed extract, a commonly used treatment for cancer in China, inhibits NFkappaB and protein kinase C signaling. Cancer Biol Ther 6: 2005-2011. 
Wu G, Yu G, Li J, et al. 2010. Short term therapeutic effect on treatment of postoperational large intestine carcinoma by Fupiyiwei decoction combined with chemotherapy and it's effect on immune function. Chin J Chin materia medica 35: 782-785.

Wu G, Yu G, Li J, et al. 2010. Short term therapeutic effect of Fupi Yiwei decoction combined with chemotherapy on postoperational large intestine cancer patients and it's effect on immune function. Chin J Chinese materia medica 35: 782-785.

Wu T, Li Y, Bian Z, et al. 2009. Randomized trials published in some Chinese journals: how many are randomized? Trials 10: 46.

Wu T, Munro A, Guanjian L, et al. 2005. Chinese medical herbs for chemotherapy side effects in colorectal cancer patients, Cochrane Database of Syst Rev. John Wiley \& Sons, Ltd, Chichester, UK.

Xu L, Lao LX, Ge A, et al. 2007. Chinese herbal medicine for cancer pain. Integ Cancer Ther 6: 208234.

Xu YX, and Wang SL. 2010. Clinical observation of Jiangniling combined with chemotherapy treatment on advanced colorectal cancer. China Medical Herald 7: 84-85.

Yang C, Lao Y, Wu F, et al. 2002. Advances in the study of Atractylodes macrocephala Koidz. Journal of Chinese Medicinal Materials 25: 206-208.

Yang S, Wang L, Wang S, et al. 2011. Job's tears components and bioactivity. Journal of Chinese Medicinal Materials 34: 1306-1312.

Yang YF. 2008. The comparative study of Kang'ai injection combined with FOLFOX4 regimen for advanced colorectal cancer. Master, Fujian University of Traditional Chinese Medicine, Fuzhou.

Ye Y, Wang H, Chu JH, et al. 2011. Atractylenolide II induces G1 cell-cycle arrest and apoptosis in B16 melanoma cells. J Ethnopharmacol 136: 279-282.

$\mathrm{Yu}$ W, Li B, Ren RJ, et al. 2006. The effects of matrine on cell proliferation and telomerase activity in retinoblastoma cells in vitro. Chinese journal of ophthalmology 42: 594-599.

Zeng D, Ling Y, Yang Q, et al. 2009. GinsenosideRg3 capsules combined with FOLFOX4 regimen for treatment of advanced colon cancer: a report of 35 cases. Journal of Bengbu Medical College 34: 1092-1094.

Zeng JQ, Li ZP, and Wang X. 2008. Traditional Chinese medicine with chemotherapy treatment on advanced colorectal carcinoma: reported of 30 cases. Journal of Jiangxi University of Traditional Chinese Medicine 20: 39-41.

Zhang HT, Fang CT, Huang ZY, et al. 2008. Clinical observation of integrated Chinese medicine and chemotherapy on 31 cases of advanced colon cancer. Journal of New Chinese Medicine 40: 22-23.

Zhang JF, He ML, Qi D, et al. 2011. Aqueous extracts of Fructus Ligustri Lucidi enhance the sensitivity of human colorectal carcinoma DLD-1 cells to doxorubicin-induced apoptosis via Tbx3 suppression. Integr Cancer Ther 10: 85-91.

Zhang Q, Wang XM, and Yang GW. 2010a. Clinical research of Guben Xiaoliu Capsule combined with FOLFOX4 plan for treatment of advanced colorectal cancer. Beijing Journal of Traditional Chinese Medicine 14: 255-257.

Zhang Y, Xu J, and Sun J. 2010b. Clinical study of Jianpi Jiedu decoction plus FOLFOX4 regimen in the treatment of advanced colorectal cancer. Global Traditional Chinese Medicine 3: 117-120.

Zhong LL, Chen HY, Cho WC, et al. 2012. The efficacy of Chinese herbal medicine as an adjunctive therapy for colorectal cancer: a systematic review and meta-analysis. Complement Ther Med 20: $240-252$.

Zhu XL and Zhu BD. 2007. Mechanisms by which Astragalus membranaceus injection regulates hematopoiesis in myelosuppressed mice. Phytotherapy Research 21: 663-667.

Zhuang SR, Chen SL, Tsai JH, et al. 2009. Effect of citronellol and the Chinese medical herb complex on cellular immunity of cancer patients receiving chemotherapy/radiotherapy. Phytotherapy Research 23: 785-790.

Zong A, Cao H, and Wang F. 2012. Anticancer polysaccharides from natural resources: A review of recent research. Carbohydrate Polymers 90: 1395-1410. 


\section{Figure Titles and Legends}

Fig 1. Flow diagram of the search and selection process of RCTs of FOLFOX4 combined with herbal medicine (HM) for advanced colorectal cancer (ACRC)

Fig 2. Funnel Plot of the 12 studies that reported tumor response rate (tRR)

Label for X axis: Risk Ratio (RR) for tumor response rate (tRR)

Label for Y axis: Sample size of study 
Table 1 Characteristics of the thirteen studies included in the analysis

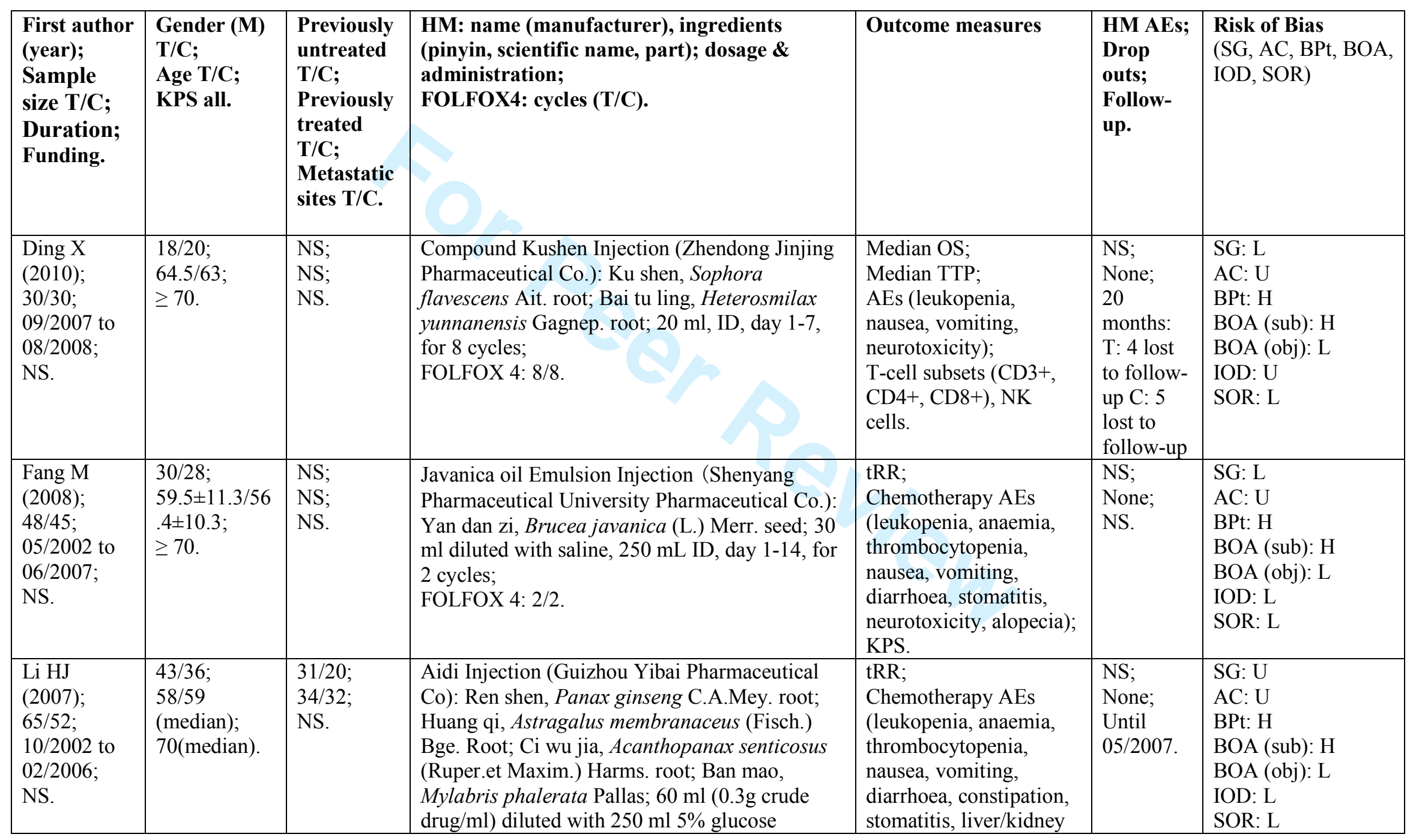




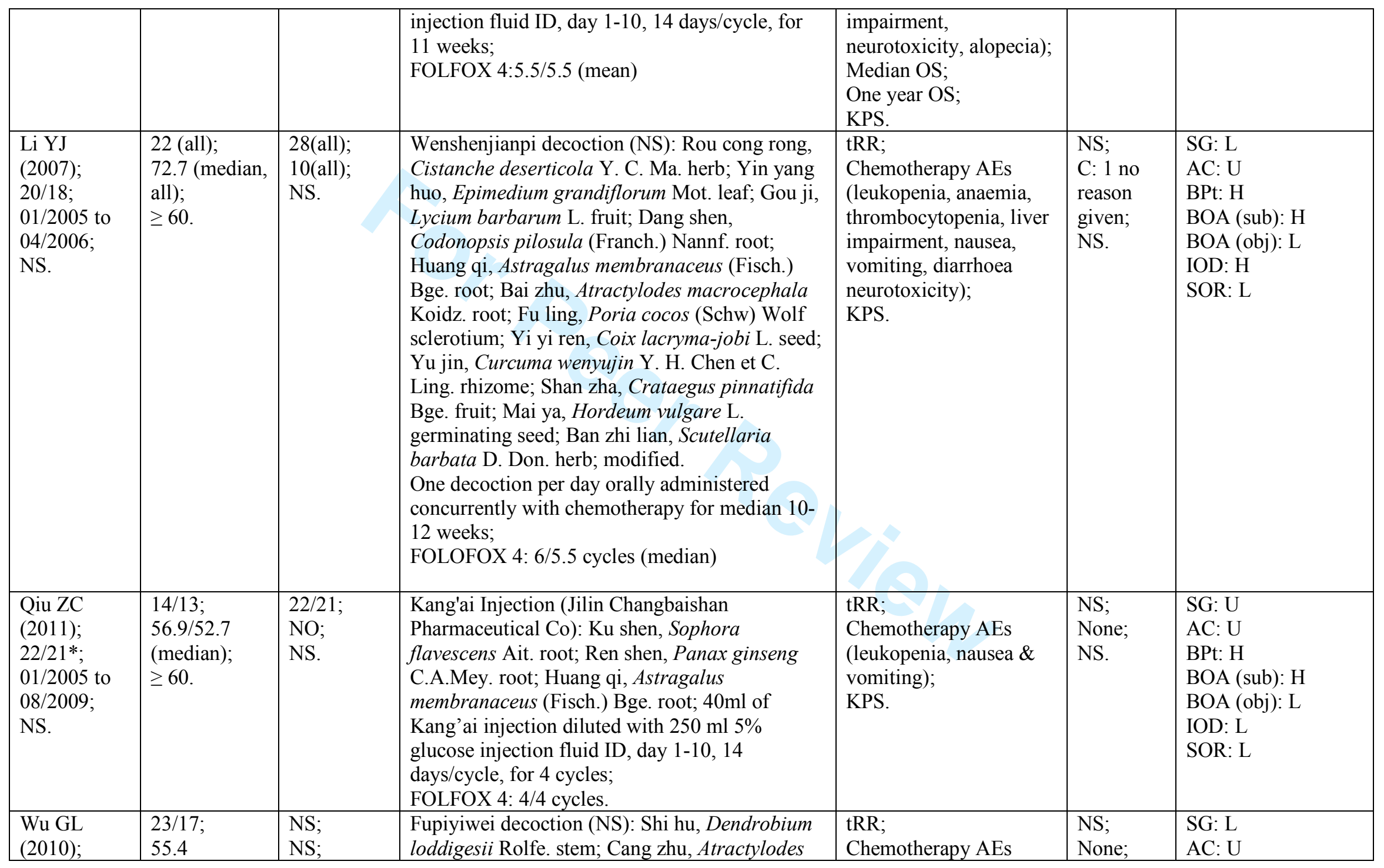




\begin{tabular}{|c|c|c|c|c|c|c|}
\hline $\begin{array}{l}33 / 25 ; \\
10 / 2004 \text { to } \\
05 / 2008 ; \\
\text { Provincial } \\
\text { fund. }\end{array}$ & $\begin{array}{l} \pm 13.6 / 52.8 \\
\pm 15.2 \\
\text { (mean); } \\
\geq 60 .\end{array}$ & NS. & $\begin{array}{l}\text { lancea (Thumb.) DC. root; Yi yi ren, Coix } \\
\text { lacryma-jobi L. seed; Ban xia Pinellia ternata } \\
\text { (Thunb.) Breit. tuber; Shan yao, Dioscorea } \\
\text { opposita Thunb. rhizome; Fu ling, Poria cocos } \\
\text { (Schw) Wolf. sclerotium; Dou kou, Alpinia } \\
\text { katsumadai Hayata. seed; Jiao gu lan, } \\
\text { Gynostemma pentaphyllum (Thunb.) Mak. herb; } \\
\text { Bai shao, Paeonia lactiflora Pall. root; Huo } \\
\text { xiang, Pogostemon cablin (Blanco) Benth. herb; } \\
\text { One decoction per day oral-administered } \\
\text { concurrently with chemotherapy for } 24 \text { weeks; } \\
\text { FOLFOX 4:12/12 cycles }\end{array}$ & $\begin{array}{l}\text { (leukopenia, anaemia, } \\
\text { thrombocytopenia, } \\
\text { nausea, vomiting, } \\
\text { diarrhoea neurotoxicity); } \\
\text { KPS; } \\
\text { T-cell subsets (CD3+, } \\
\text { CD4+, CD8+), NK } \\
\text { cells. }\end{array}$ & NS. & $\begin{array}{l}\text { BPt: H } \\
\text { BOA (sub): H } \\
\text { BOA (obj): L } \\
\text { IOD: L } \\
\text { SOR: L }\end{array}$ \\
\hline $\begin{array}{l}\text { Xu YX } \\
(2010) ; \\
61 / 60 ; \\
08 / 2004 \text { to } \\
11 / 2008 ; \\
\text { NS. }\end{array}$ & $\begin{array}{l}38 / 37 ; \\
53 / 52 \\
\text { (mean); } \\
\geq 70 .\end{array}$ & $\begin{array}{l}\text { NS; } \\
\text { NS; } \\
\text { NS. }\end{array}$ & $\begin{array}{l}\text { Jiangniling decoction (NS): Dang shen, } \\
\text { Codonopsis pilosula (Franch.) Nannf. root; Bai } \\
\text { zhu, Atractylodes macrocephala Koidz. root; Fu } \\
\text { ling, Poria cocos (Schw) Wolf. sclerotium; Bai } \\
\text { dou kou, Amomum cardamomum L. seed, Ban } \\
\text { xia, Pinellia ternata (Thunb.) Breit. tuber; Sha } \\
\text { ren, Amomum villosum Lour. seed; Xiang fu, } \\
\text { Cyperus rotundus L. rhizome; Chen pi, Citrus } \\
\text { reticulata Blanco. peel; Zhu ru, Phyllostachyl } \\
\text { nigra (Lodd.). shaving; Sheng jiang, Zingiber } \\
\text { officinale Rosc. rhizome; Yi yi ren, Coix } \\
\text { lacryma-jobi L. seed; One decoction per day } \\
\text { orally administered concurrently with } \\
\text { chemotherapy for } 22 \text { weeks; } \\
\text { FOLFOX 4: } 11.1 / 7.8 \text { cycles (mean). }\end{array}$ & $\begin{array}{l}\text { tRR; } \\
\text { Chemotherapy AEs } \\
\text { (nausea, vomiting, } \\
\text { diarrhoea, anaemia, } \\
\text { leukopenia, } \\
\text { thrombocytopenia); } \\
\text { TTP; } \\
\text { KPS. }\end{array}$ & $\begin{array}{l}\text { NS; } \\
\text { None; } \\
\text { NS. }\end{array}$ & $\begin{array}{l}\text { SG: U } \\
\text { AC: U } \\
\text { BPt: H } \\
\text { BOA (sub): H } \\
\text { BOA (obj): L } \\
\text { IOD: L } \\
\text { SOR: L }\end{array}$ \\
\hline $\begin{array}{l}\text { Yang YF } \\
\text { (2008); } \\
30 / 30 ; \\
01 / 2007 \text { to } \\
11 / 2007 ; \\
\text { NS. }\end{array}$ & $\begin{array}{l}16 / 19 \\
51.07 \pm 10.44 / \\
51.33 \\
\pm 10.95 \\
\text { (mean); } \\
40.73 \pm 3.49 / \\
40.90 \pm 2.44\end{array}$ & $\begin{array}{l}9 / 7 ; \\
21 / 23 ; \\
\text { NS. }\end{array}$ & $\begin{array}{l}\text { Kang'ai Injection (Jilin Changbaishan } \\
\text { Pharmaceutical Co): Ku shen, Sophora } \\
\text { flavescens Ait. root; Ren shen, Panax ginseng } \\
\text { C.A.Mey. root; Huang qi, Astragalus } \\
\text { membranaceus (Fisch.) Bge. root; } 50 \mathrm{ml} \text { of } \\
\text { Kang'ai injection diluted with } 250 \mathrm{ml} 5 \% \\
\text { glucose injection fluid ID per day, day 1-20, } 30 \\
\text { days/course, for } 2 \text { courses; }\end{array}$ & $\begin{array}{l}\text { tRR; } \\
\text { Chemotherapy AEs } \\
\text { (leukopenia, anaemia, } \\
\text { thrombocytopenia, liver } \\
\text { impairment, nausea, } \\
\text { vomiting, diarrhoea, } \\
\text { neurotoxicity); } \\
\text { QOL, BW. }\end{array}$ & $\begin{array}{l}\text { NS; } \\
\text { None; } \\
\text { NS. }\end{array}$ & $\begin{array}{l}\text { SG: U } \\
\text { AC: U } \\
\text { BPt: H } \\
\text { BOA (sub): H } \\
\text { BOA (obj): L } \\
\text { IOD: L } \\
\text { SOR: L }\end{array}$ \\
\hline
\end{tabular}




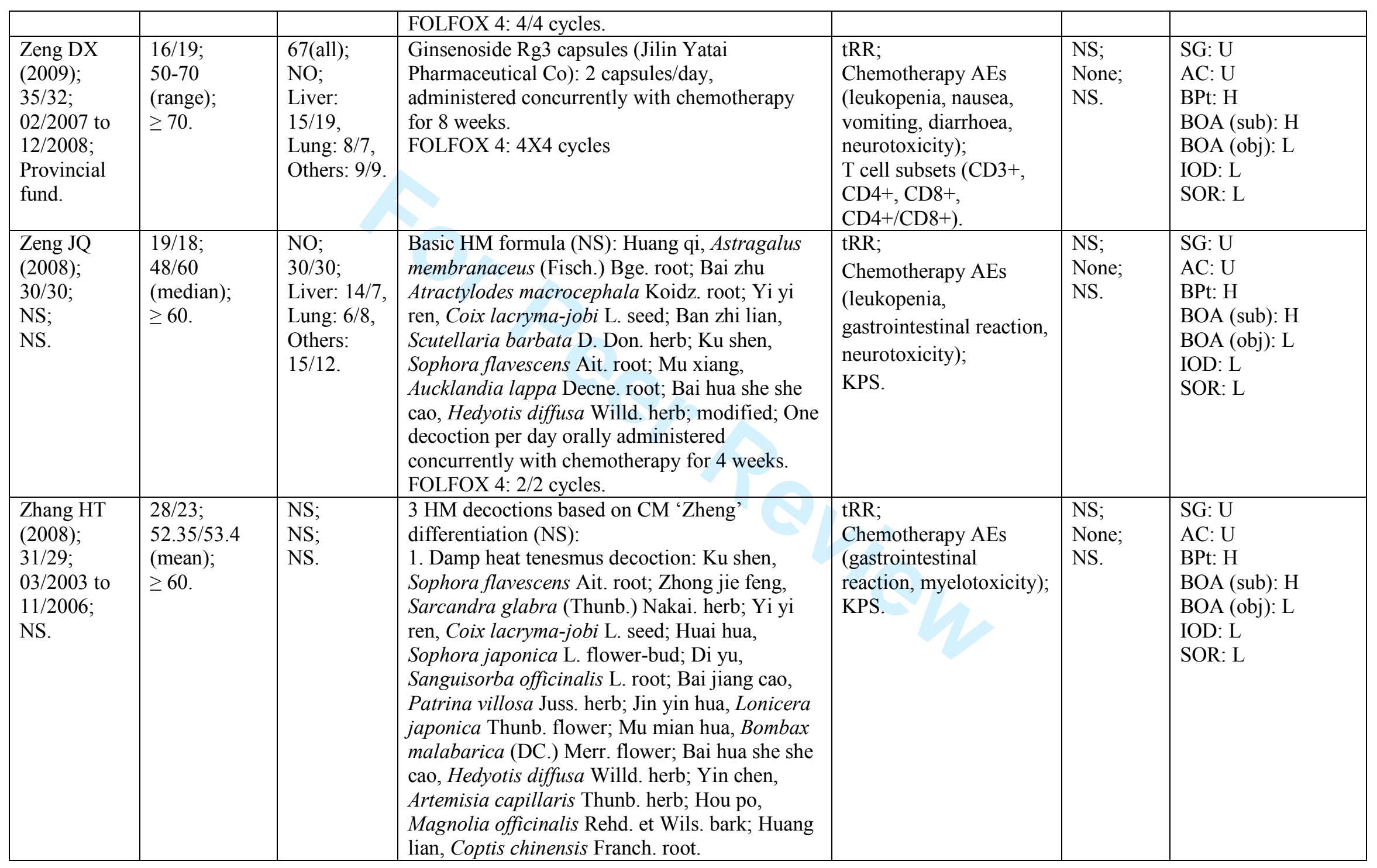




\begin{tabular}{|c|c|c|c|c|c|c|}
\hline & & & $\begin{array}{l}\text { 2. Toxic stasis in colon decoction: Ku shen, } \\
\text { Sophora flavescens Ait. root; Zhong jie feng, } \\
\text { Sarcandra glabra (Thunb.) herb; Huai hua, } \\
\text { Sophora japonica L. flower-bud; Di yu, } \\
\text { Sanguisorba officinalis L. root; Bai jiang cao, } \\
\text { Patrina villosa Juss. herb; Jin yin hua, Lonicera } \\
\text { japonica Thunb. flower; Bai hua she she cao, } \\
\text { Hedyotis diffusa Willd. herb; Yan dan zi, Brucea } \\
\text { javanica (L.) Merr. seed; Da ji, Cirsium } \\
\text { japonicum DC. herb; Qi ye yi zhi hua, Paris } \\
\text { polyphylla Smith. root; Chi shao, Paeonia } \\
\text { veitchii Lynch. root; E zhu, Curcumae } \\
\text { phaeocaulis Val. rhizome; } \\
\text { 3. Spleen and kidney deficiency decoction: Dang } \\
\text { shen, Codonopsis pilosula (Franch.) Nannf. root; } \\
\text { Fu ling, Poria cocos (Schw) Wolf. sclerotium; } \\
\text { Huang qi, Astragalus membranaceus (Fisch.) } \\
\text { Bge. root; Ku shen, Sophora flavescens Ait. } \\
\text { root; Zhong jie feng, Sarcandra glabra (Thunb.) } \\
\text { Nakai. herb; Yi yi ren, Coix lacryma-jobi L. } \\
\text { seed; Sha ren, Amomum villosum Lour. seed, } \\
\text { Lian zi, Nelumbo nucifera Gaertn. Seed; Bai } \\
\text { zhu, Atractylodes macrocephala Koidz. root; He } \\
\text { zi, Terminalia chebula Retz. seed; He shou wu, } \\
\text { Polygonum multiflorum Thunb. root; Bai shao, } \\
\text { Paeonia lactiflora Pall. root; } \\
\text { One decoction per day orally administered } \\
\text { concurrently with chemotherapy. Started one } \\
\text { week before chemotherapy till one week after } \\
\text { chemotherapy completed. } \\
\text { FOLFOX 4: 4/4 cycles. }\end{array}$ & & & \\
\hline $\begin{array}{l}\text { Zhang Q } \\
(2010) ; \\
60 / 60 ; \\
02 / 2005 \text { to }\end{array}$ & $\begin{array}{l}35 / 33 \\
56.2(\text { mean } \\
\text { all); } \\
\geq 60\end{array}$ & $\begin{array}{l}32 / 34 \\
\text { 28/26; } \\
\text { Liver: } \\
32 / 36\end{array}$ & $\begin{array}{l}\text { Guben Xiaoliu Capsule (Beijing Chinese } \\
\text { Medicine Hospital, affiliated with Beijing } \\
\text { Medical University): Dong chong xia cao, } \\
\text { Cordyceps sinensis (Berk.) Sacc. ascocarp and }\end{array}$ & $\begin{array}{l}\text { tRR; } \\
\text { Chemotherapy AEs } \\
\text { (leukopenia, anaemia, } \\
\text { thrombocytopenia, }\end{array}$ & $\begin{array}{l}\text { NS; } \\
\text { None; } \\
\text { Until }\end{array}$ & $\begin{array}{l}\text { SG: L } \\
\text { AC: } \mathrm{U} \\
\text { BPt: H } \\
\text { BOA (sub): H }\end{array}$ \\
\hline
\end{tabular}




\begin{tabular}{|c|c|c|c|c|c|c|}
\hline $\begin{array}{l}\text { 10/2007; } \\
\text { Provincial } \\
\text { fund. }\end{array}$ & & $\begin{array}{l}\text { Lung: } \\
\text { 16/19, } \\
\text { Others: } \\
51 / 39 \text {. }\end{array}$ & $\begin{array}{l}\text { dead larva; Ling zhi, Ganoderma lucidum } \\
\text { (Leyss. ex Fr.) Karst. sporocarp; Yin yang huo, } \\
\text { Epimedium grandiflorum Mot. leaf; Zhe bei mu, } \\
\text { Fritillaria thunbergii Miq. bulb; Xi yang shen, } \\
\text { Panax quinquefolium L. root; Yi yi ren, Coix } \\
\text { lacryma-jobi L. seed; Shui zhi, Hirudo } \\
\text { nipponica Whitman. whole leech; Quan xie, } \\
\text { Buthus martensii Karsch. whole insect; Long } \\
\text { kui, Solanum nigrum L. herb; } 4 \text { capsules each } \\
\text { time, twice a day, orally administered } \\
\text { concurrently with chemotherapy for } 8 \text { wks. } \\
\text { FOLFOX 4: } 4 / 4 \text { cycles. }\end{array}$ & $\begin{array}{l}\text { nausea \& vomiting, } \\
\text { diarrhoea, } \\
\text { neurotoxicity); } \\
\text { KPS; } \\
\text { T cell subsets } \\
\text { CD4+/CD8+, } \\
\text { NK cells. }\end{array}$ & $07 / 2008$ & $\begin{array}{l}\text { BOA (obj): L } \\
\text { IOD: L } \\
\text { SOR: L }\end{array}$ \\
\hline $\begin{array}{l}\text { Zhang Y } \\
(2010) ; \\
21 / 20 ; \\
01 / 2005 \text { to } \\
12 / 2008 ; \\
\text { State fund. }\end{array}$ & $\begin{array}{l}\text { NS; } \\
\text { NS; } \\
\geq 60\end{array}$ & $\begin{array}{l}\text { NS; } \\
\text { NS; } \\
\text { NS. }\end{array}$ & $\begin{array}{l}\text { Jianpi Jiedu decoction (NS): Huang qi, } \\
\text { Astragalus membranaceus (Fisch.) Bge. root; } \\
\text { Bai zhu, Atractylodes macrocephala Koidz. } \\
\text { root; Ba yue zha, Akebia quinata (Thunb.) } \\
\text { Decne. fruit; Shi jian chuan, Salvia chinensis } \\
\text { Benth. herb; Ye pu tao teng, Vitis } \\
\text { quinquangularis Rehder. vine and leaf; One } \\
\text { decoction per day orally administered } \\
\text { concurrently with chemotherapy, for } 4 \text { weeks. } \\
\text { FOLFOX 4: } 2 / 2 \text { cycles }\end{array}$ & $\begin{array}{l}\text { tRR; } \\
\text { Chemotherapy AEs } \\
\text { (leukopenia, anaemia, } \\
\text { thrombocytopenia, liver } \\
\text { impairment, nausea \& } \\
\text { vomiting, } \\
\text { neurotoxicity); } \\
\text { TTP; One year OS; } \\
\text { Median OS; } \\
\text { KPS; BW. }\end{array}$ & $\begin{array}{l}\text { NS, } \\
\text { C: } 1 \text { no } \\
\text { reason; } \\
\text { Until } \\
11 / 2009 .\end{array}$ & $\begin{array}{l}\text { SG: U } \\
\text { AC: U } \\
\text { BPt: H } \\
\text { BOA (sub): H } \\
\text { BOA (obj): L } \\
\text { IOD: H } \\
\text { SOR: L }\end{array}$ \\
\hline
\end{tabular}

T: treatment group, C: control group, M: male, N: number, NS: not stated, ID: intravenous drip, tRR: Tumor Response Rate; BW: Body Weight; QOL: Quality of Life; TTP: Time to Progression; OS: Overall Survival; KPS: Karnofsky Performance Status; CM: Chinese medicine; HM: herbal medicine.

* note error in method section which states 20 in control, whereas elsewhere the number is 21.

Risk of Bias Categories

SG: Sequence Generation, AC: Allocation Concealment, BPt: Blinding of Participants/Personnel, BOA (sub): Blinding of Outcome Assessment (subjective measures), BOA (obj): Blinding of Outcome Assessment (objective measures), IOD: Incomplete Outcome Data, SOR: Selective Outcome Reporting.

Risk of Bias Judgements

L: low risk, U: Unclear risk, H: High risk 
Table 2: Results of meta-analyses for each outcome measure

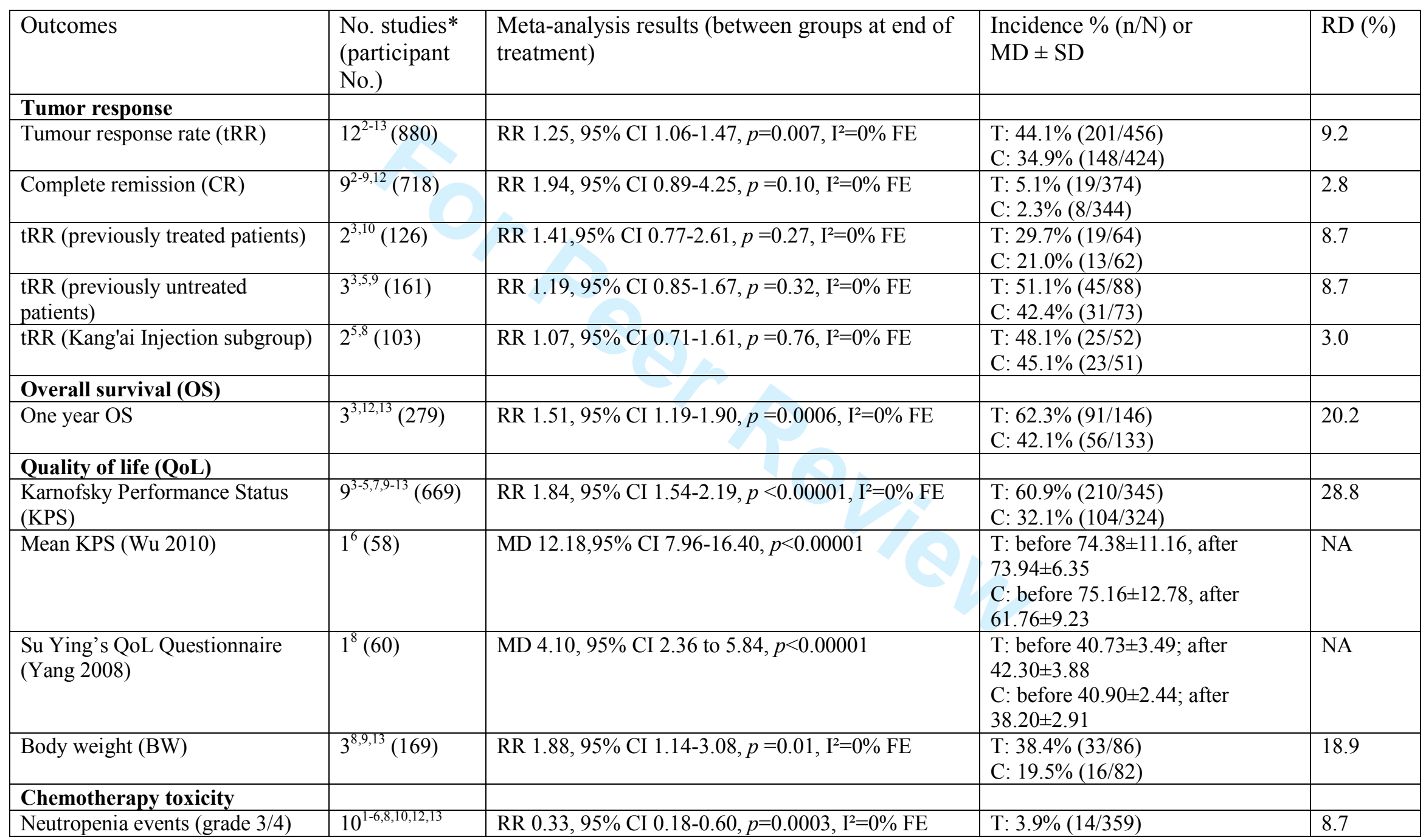




\begin{tabular}{|c|c|c|c|c|}
\hline & $(692)$ & & C: $12.6 \%(42 / 333)$ & \\
\hline Neurotoxicity (grade 3/4) & $7^{1-4,12,13}(529)$ & RR $0.39,95 \%$ CI $0.15-1.00, p=0.05, \mathrm{I}^{2}=0 \% \mathrm{FE}$ & $\begin{array}{l}\text { T: } 2.2 \%(6 / 277) \\
\text { C: } 6.0 \%(15 / 252)\end{array}$ & 3.8 \\
\hline Anaemia (grade 3/4) & $3^{6,12,13}(220)$ & RR $0.30,95 \%$ CI $0.05-1.89, p=0.20, \mathrm{I}^{2}=0 \% \mathrm{FE}$ & $\begin{array}{l}\text { T: } 0 \%(0 / 114) \\
\text { C: } 2.9 \%(3 / 105)\end{array}$ & 2.9 \\
\hline Stomatitis (grade $3 / 4$ ) & $2^{2,3}(210)$ & RR $0.43,95 \%$ CI $0.08-2.31, p=0.33, I^{2}=0 \%$ FE & $\begin{array}{l}\text { T: } 1.8 \%(2 / 113) \\
\text { C: } 4.1 \%(4 / 97)\end{array}$ & 2.3 \\
\hline Constipation (grade 3/4) & $1^{3}(117)$ & RR $0.40,95 \%$ CI $0.04-4.29, p=0.45 \mathrm{FE}$ & $\begin{array}{l}\text { T: } 1.5 \%(1 / 65) \\
\text { C: } 3.8 \%(2 / 52)\end{array}$ & NA \\
\hline Myolesuppression (grade 3) & $1^{11}(60)$ & RR $0.47,95 \%$ CI $0.04-4.89, p=0.53 \mathrm{FE}$ & $\begin{array}{l}\text { T: } 3.23 \%(1 / 31) \\
\text { C: } 6.90 \%(2 / 29)\end{array}$ & NA \\
\hline Kang'ai Injection Subgroup & & 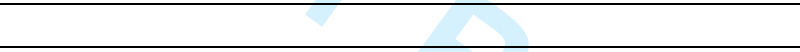 & & \\
\hline \multicolumn{5}{|l|}{ Immune function } \\
\hline CD3+ cells $(\%)$ & $2^{1,6}(118)$ & MD $4.70,95 \%$ CI 2.27 to $7.13, p=0.0001, \mathrm{I}^{2}=37 \% \mathrm{FE}$ & NA & NA \\
\hline CD4+ cells $(\%)$ & $2^{1,6}(118)$ & MD $9.08,95 \%$ CI 0.10 to $18.05, p=0.05, \mathrm{I}^{2}=95 \% \mathrm{RE}$ & NA & NA \\
\hline CD8+ cells $(\%)$ & $2^{1,6}(118)$ & MD $-4.47,95 \%$ CI -9.54 to $0.61, p=0.08, \mathrm{I}^{2}=87 \% \mathrm{RE}$ & NA & NA \\
\hline Ratio CD4+/CD8+ & $2^{1,12}(180)$ & MD $0.28,95 \%$ CI 0.14 to $0.43, p=0.0002, I^{2}=13 \% \mathrm{FE}$ & NA & NA \\
\hline NK cells $(\%)$ & $3^{1,6,12}(238)$ & MD $4.03,95 \%$ CI 0.51 to $7.55, p=0.02, I^{2}=88 \% \mathrm{RE}$ & NA & NA \\
\hline
\end{tabular}

T: test group; C: control group; RR: risk ratio; N: total number of participants in group(s); n: number of events in group(s); $\mathrm{I}^{2}$ : test of heterogeneity of metaanalysis, over 50\% represents substantial heterogeneity; MD: mean difference; SD standard deviation; RD: Risk difference; NA: not applicable; FE: Fixed Effect model; RE: Random Effect model.

*Included studies: 1. Ding X 2010, 2. Fang M 2008, 3. Li H 2007, 4. Li Y 2007, 5. Qiu Z 2011, 6. Wu G 2010, 7. Xu Y 2010, 8. Yang F 2008, 9. Zeng D 2009 , 10. Zeng J 2008, 11. Zhang H 2008, 12. Zhang Q 2010a, 13. Zhang Y 2010 b. 


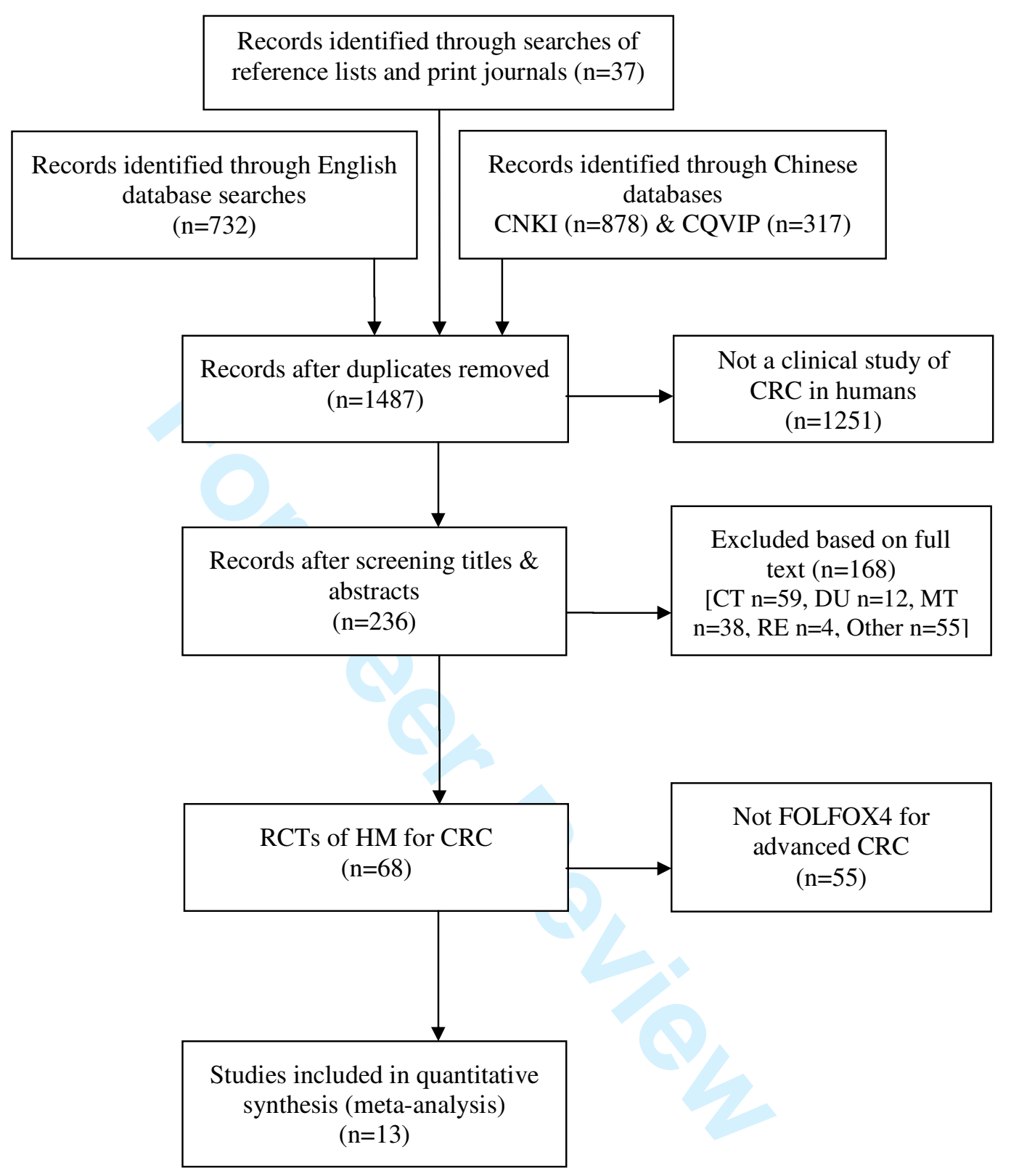

Fig 1. Flow diagram of the search and selection process of RCTs of FOLFOX4 combined with herbal medicine (HM) for advanced colorectal cancer (ACRC)

CT: clinical trial of HM without randomisation; DU: duplicate publication; MT: multi-cancer CT; RE: review; Other: not a controlled trial, or not a CT of HM, or outcome is not efficacy. 


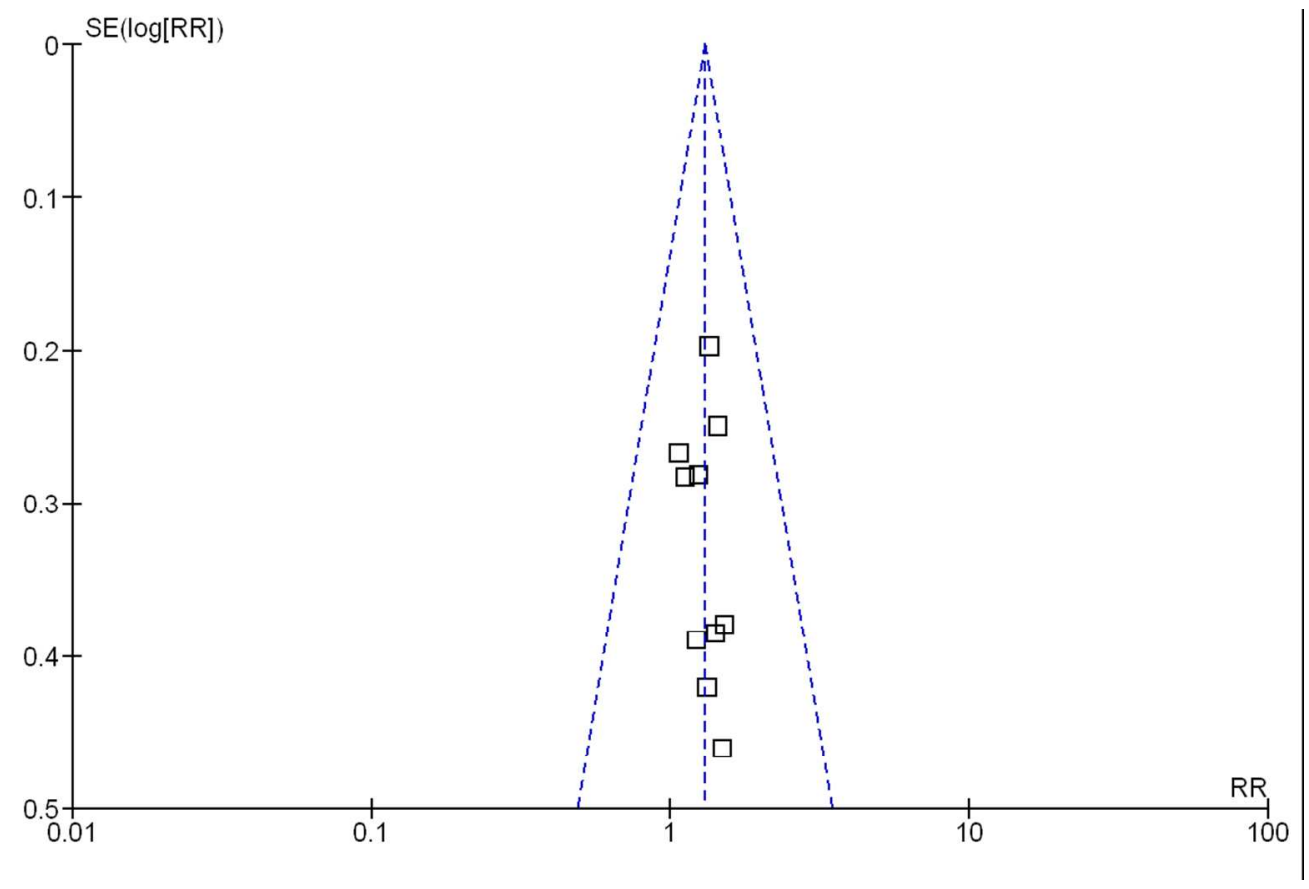

Fig 2. Funnel Plot of the 12 studies that reported tumor response rate (tRR) $192 \times 171 \mathrm{~mm}(152 \times 114 \mathrm{DPI})$ 